\title{
Postanesthetic skin erythema due to succinylcholine versus atracurium
}

\author{
OANA ROXANA CIOBOTARU ${ }^{1 *}$, GABRIELA STOLERIU $^{1}$, OCTAVIAN CATALIN CIOBOTARU ${ }^{2}$, \\ ALEXANDRU GRIGOROVICI $^{3}$, DOINA CARINA VOINESCU ${ }^{1 *}$, MADALINA NICOLETA MATEI $^{4 *}$, \\ ROXANA GABRIELA COBZARU ${ }^{5 *}$, NICUTA MANOLACHE ${ }^{6}$ and MARY-NICOLETA LUPU ${ }^{2}$ \\ ${ }^{1}$ Clinical Department and ${ }^{2}$ Department of Surgery, Faculty of Medicine and Pharmacy, 'Dunărea de Jos' University, \\ 800008 Galati; ${ }^{3}$ Department of Surgery, 'Grigore T. Popa' University of Medicine and Pharmacy, 700115 Iasi; \\ ${ }^{4}$ Department of Dental Medicine, Faculty of Medicine and Pharmacy, 'Dunărea de Jos' University, 800008 Galati; \\ ${ }^{5}$ Department of Preventive Medicine and Interdisciplinarity, Discipline Microbiology, \\ 'Grigore T. Popa' University of Medicine and Pharmacy, 700115 Iasi; ${ }^{6}$ Department of Pharmaceutical Sciences, \\ Faculty of Medicine and Pharmacy, 'Dunărea de Jos' University, 800008 Galati, Romania
}

Received March 13, 2020; Accepted April 14, 2020

DOI: $10.3892 /$ etm.2020.8792

\begin{abstract}
Intraoperative anaphylactic reactions may range from mild, erythema-like to anaphylactic shock, with tension crash and bronchospasm. The substances considered to be most responsible for the occurrence of intraoperative allergic reactions are neuromuscular blocking agents, antibiotics and latex. Recent studies have identified a new receptor, Mas-Related G-Protein-coupled Receptor X2 (MRGPRX2), considered as a target for some neuromuscular blockers such as atracurium, rocuronium or fluoroquinolone, resulting in pseudoallergic or anaphylactoid reactions. Induction of anesthesia can use both depolarizing myorelaxants, useful especially in emergency situations, in the patient with gastric plenitude or at high risk of intubation, and non-depolarizing myorelaxants such as atracurium, cisatracurium and rocuronium. Succinylcholine has a short time of action and it is rapidly metabolized. Atracurium, although having a slightly longer time to action, has the benefit of a low risk of increased levels of potassium in blood, which is extremely important in patients with cardiac pathology or associated kidney diseases. The present study compared the
\end{abstract}

Correspondence to: Professor Gabriela Stoleriu, Clinical Department, Faculty of Medicine and Pharmacy, 'Dunărea de Jos' University, 35 Al. I. Cuza Street, 800008 Galati, Romania

E-mail: stoleriugabriela@yahoo.com

Professor Octavian Catalin Ciobotaru, Department of Surgery, Faculty of Medicine and Pharmacy, 'Dunărea de Jos' University, 35 Al. I. Cuza Street, 800008 Galati, Romania

E-mail: coctavian72@gmail.com

*Contributed equally

Key words: succinylcholine, atracurium, erythema, depolarizing myorelaxants, non-depolarizing myorelaxants, postanesthetic side effects side effects of systemic anesthesia with succinylcholine vs. atracurium.

\section{Introduction}

Intraoperative anaphylactic reactions may range from mild, erythema-like to anaphylactic shock, with tension crash and bronchospasm (1). Usually, severe allergic reactions which results in vertigo or loss of consciousness is preceded by intense itching, redness and swelling over some body areas, new skin eruption or hives, runny nose, itchy eyes and later on, a feeling of light-headedness, as if the world is turning, then followed by vertigo. Anaphylaxis during anesthesia is an unpredictable, severe, and rare reaction. The substances considered to be most responsible for the occurrence of intraoperative allergic reactions are neuromuscular blocking agents, antibiotics and latex (2). Allergic reactions to latex occur intraoperatively as time is needed to absorb the allergen through the mucosa or peritoneum.

\section{Patients and methods}

A retrospective study was conducted in two hospitals on a total of 905 patients divided into two groups, depending on the muscle relaxant used in induction: Succinylcholine or atracurium.

Because the purpose of the study was to follow the allergic reactions of succinylcholine versus atracurium, all other medications used in induction were identical, both as an order of administration, and as a dose in relation to the patient's weight.

In order to maintain anesthesia, atracurium was always used as a muscle relaxant.

Immediate allergic reaction consisting of erythema on the face, neck and/or upper back, post-induced anesthesia with succinylcholine or atracurium, within the first $10 \mathrm{~min}$ after administration of myorelaxant, was observed, noted and described. 
Table I. Descriptive statistics of the two groups: Succinylcholine and atracurium.

\begin{tabular}{lccccc}
\hline & \multicolumn{2}{c}{ Succinylcholine } & & \multicolumn{2}{c}{ Atracurium } \\
\cline { 2 - 3 } \cline { 5 - 6 } Variables & $\begin{array}{c}\text { Frequency } \\
(\mathrm{n})\end{array}$ & $\begin{array}{c}\text { Percent } \\
(\%)\end{array}$ & & $\begin{array}{c}\text { Frequency } \\
(\mathrm{n})\end{array}$ & $\begin{array}{c}\text { Percent } \\
(\%)\end{array}$ \\
\hline Sex & & & & & \\
$\quad$ Female & 376 & 82.6 & & 136 & 30.2 \\
Male & 79 & 17.4 & & 314 & 69.8 \\
BMI, kg/m & & & & & \\
$<18.5$ & 71 & 15.6 & & 25 & 5.6 \\
$18.5-24.9$ & 172 & 37.8 & & 215 & 47.8 \\
$25-29.9$ & 127 & 27.9 & & 139 & 30.9 \\
$30-34.9$ & 65 & 14.3 & & 46 & 10.2 \\
$35-39.9$ & 20 & 4.4 & & 25 & 5.6 \\
Age, years & & & & \\
$<40$ & 65 & 14.3 & & 35 & 7.8 \\
$40-60$ & 259 & 56.9 & & 190 & 42.2 \\
$>60$ & 131 & 28.8 & & 225 & 50.0 \\
Provenance & & & & & \\
$\quad$ Urban & 172 & 37.8 & & 225 & 50 \\
Rural & 283 & 62.2 & & 225 & 50 \\
\hline
\end{tabular}

The doses administered were $1 \mathrm{mg} / \mathrm{kg}$ succinylcholine $($ Lysthenon $=$ Suxamethonium chloride, $0.1 \mathrm{~g} / 5 \mathrm{ml}$; Takeda $)$ and $0.4-0.5 \mathrm{mg} / \mathrm{kg}$ over $60 \mathrm{sec}$, atracurium (Tracrium = atracurium besylate, $50 \mathrm{mg} / 5 \mathrm{ml}$; Aspen) according to 'Morgan and Mikhail's Clinical Anesthesiology' (3).

Inclusion criteria: Patients undergoing surgery under general anesthesia, scheduled surgical operations, signed informed consent from the patients involved in the study, according to ethical requirements (4).

Exclusion criteria: patients in whom surgery was performed in an emergency, patients whose surgery started with locoregional anesthesia then converted into general anesthesia, patients whose anesthesia was performed or continued by other anesthesiologists, patients with a history of allergic reactions to drugs or food, patients with asthma.

The present study is a retrospective study based on the side effects to drugs that were already included in the treatment protocol, according to 'Morgan and Mikhail's Clinical Anesthesiology', and are commonly used for anesthesia in the clinic. Signed informed consent was obtained from each patient.

Statistical analysis. The analyzed database stores the information in the form of nominal/categorical variables (sex, place of origin, if the patient had erythema, type of anesthetics, age groups or BMI groups). The relationships between variables were determined by calculating the values of the correlation coefficients at nominal level $\phi, \mathrm{C}$ and $\mathrm{V}$, as well as the probabilities associated with them. If the associated probability, $\mathrm{P}<\alpha=0.05$ (the significance threshold), it results in variables that are correlated (there is a dependency relationship between them) $(5,6)$. The values of the coefficients show how strong the

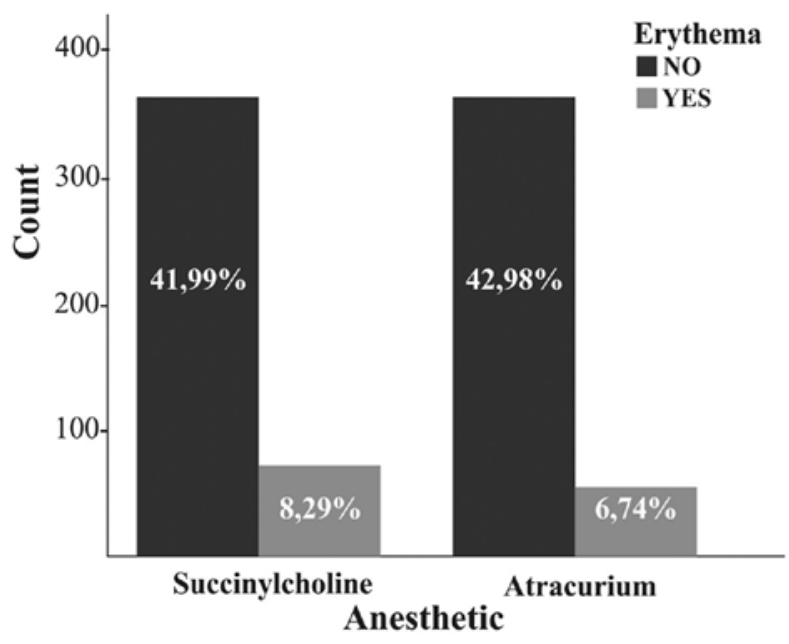

Figure 1. The presence of erythema after injecting myorelaxant.

correlation is. The choice of correlation tests depends on the type of data and the number of possible variants for each of the variables analyzed.

Another method for determining the degree of association between two categorical variables is the Pearson Chi-square test.

The software package used for statistical analysis was IBM SPSS Statistics version 23.

\section{Results}

The 905 patients under study were divided into two groups. In the first group, consisting of 455 subjects, anesthesia was induced by succinylcholine, and the second group, consisting of 450 subjects, by atracurium (Table I).

Looking at the entire study group, analyzing the occurrence of erythema within the first $10 \mathrm{~min}$ after injection of myorelaxant in induction phase of anesthesia, a higher frequency was found in patients who received succinylcholine (Fig. 1).

The statistical analysis revealed a poor correlation between the type of subjects and the occurrence of erythema after the muscle relaxant in the case of succinylcholine $(\mathrm{P}<0.001<\alpha=0.05 ; \phi=-0.204)$ and in the case of atracurium $(\mathrm{P}=0.023<\alpha=0.05 ; \phi=-0.107)$, women being the most affected. Post-induction allergic reaction was found in $19.94 \%$ of patients who received Lysthenon and none was male in this group, and in the second group of atracurium, in $19.11 \%$ of the women and $11.11 \%$ of the men.

Regarding the home environment, a weak correlation ( $\mathrm{P}<0.001<\alpha=0.05, \phi=0.224)$ was observed in the succinylcholine group, most of the patients experiencing allergic reaction being urban (22.96\% of urban area vs. $5.81 \%$ in rural areas). In the second lot, between these two nominal parameters there was no statistical correlation $(\mathrm{P}=0.890>\alpha=0.05)$.

In the age groups, each of the two groups was divided into 3 subgroups: Patients up to 40 years of age, patients aged 40 to 60 , and patients over 60 years of age. Finding an average correlation between the age and the occurrence of erythema in the first group $(\mathrm{P}<0.001<\alpha=0.05, \mathrm{~V}=0.414 ; \mathrm{C}=0.382)$, the most affected being young patients under the age of $40,7 \%$ of those who experienced post-injection allergy). No relationship 
between these two parameters was observed when using atracurium $(\mathrm{P}=0.310>\alpha=0.05$.

In both groups there was a weak correlation between the body mass index and the allergic reactions occurring after induction, posterior injection of the Lysthenon $(\mathrm{P}<0.001<\alpha=0.05, \mathrm{~V}=0.218, \mathrm{C}=0.213)$ and Tracrium $(\mathrm{P}=0.002<0.05, \mathrm{~V}=0.197$ and $\mathrm{C}=0.193)$, with the highest percentage of erythema being present in overweight patients with BMI between $25-29.9 \mathrm{~kg} / \mathrm{m}^{2}$ (40\% in the first group and $50.8 \%$, in the second).

Allergic reactions, in the studied group, were only of erythematous type, which spontaneously resolved within $15 \mathrm{~min}$ of the occurrence.

\section{Discussion}

Lysthenon is a commonly used depolarizing agent. It is a drug that acts as an agonist at neuromuscular junction acetylcholine receptors which results in nerve cell depolarization that leads to sustained cell excitation. Succinylcholine results in nerve endplate resistance to further activation by acetylcholine, which paralyses the muscle. Tracrium is a highly selective, competitive or non-depolarising neuromuscular blocking agent. A neuromuscular non-depolarizing agent is a form of neuromuscular blocker that does not depolarize the motor end plate.

Isolated cutaneous reactions appear to be primarily due to non-IgE mediated anaphylaxis, and severe side effects such as arterial hypotension, bronchospasm, are due to type IgE mediated allergy mechanisms $(1,7,8)$. Other side effects may be induced by first cellular mechanisms interleukin-modulated because of topical medication or may occur on common medication and may be locally complicated (9-13).

As an intraanesthetic sensitivity response, the incidence was reported to be between 1/1,250 and 1/13,000 anesthetic interventions (8-10). Other studies have reported the incidence of anaphylactic reactions as being between $1 / 4,000$ to $1 / 25,000$ (4) and 1/5,000 of these are caused by neuro-muscular blockers (14).

The 6th National Audit Project (NAP6) that looked at perioperative anaphylactic reactions based on 266 cases reported in the United Kingdom with 3-5 grade anaphylactic reactions over a 1 year period found that $24.4 \%$ of these were due to neuromuscular blocking. Succinylcholine (depolarizing myorelaxant) is the cause of twice as frequent occurrence of anaphylactic reactions. There was no difference between non-depolarizing muscle relaxants (15).

The mechanism by which muscle relaxants cause anaphylactic reactions is either IgE-dependent, such as succinylcholine, or by direct activation of mast cells or basophils, a mechanism encountered in the case of atracurium (16).

IgE-recognized immunodominant determinant is represented by the ammonium group at the level of muscle relaxants, and cross-reactions between muscle relaxants and other perioperative substances such as neostigmine or morphine may occur $(17,18)$. IgG-mediated perioperative anaphylactic reactions are those that most commonly occur after muscle relaxants, followed by latex and antibiotics $(2,19)$.

Atracurium, being a benzyl-isoquinolinium-type muscle relaxant, produces a non-IgE-mediated anaphylactoid reaction (20-29), releases more histamine than the aminosteroid neuro-muscular blockers. This could be prevented by slow injection, possibly using antihistamines before induction (30).

From a clinical point of view, allergic immune and non-immune recurrences cannot be differentiated.

As a result of clinical phenomena, immediate reactions of hyper reactivity are classified into several degrees (31): Grade I: Cutaneous signs, generalized erythema, angioedema, urticaria; grade II: Not life-threatening, cutaneous signs, tachycardia, hypotension, respiratory dysfunction (cough, difficulty in breathing); grade III: Life threatening, arrhythmias, tachycardia or bradycardia, bronchospasm, collapse; grade IV: Cardiac/respiratory arrest (32-34). In this study, all patients were ranked grade I in severity.

Referring to patient-responsiveness, in a study published in 2018 that followed the 'skin test' response to muscle relaxants, it was found that $87 \%$ of the subjects who tested positive for this test were female, the most allergenic one being succinylcholine $(35,36)$. This study is in agreement with the results of our research, according to which a greater predisposition of the female to develop allergic reactions post-administration of muscle relaxants (37-39).

A nationwide analysis in France over the period 2000-2012 and published in 2018 that followed the occurrence of post-administration anaphylactic reactions of suxamethonium and rocuronium versus atracurium or cisatracurium found the involvement of suxamethonium in $64 \%$ of the adverse reactions (40).

Finally, we wondered if it would justify skin testing of all patients preoperatively. The Petipain study considers that skin tests should be performed more frequently in order to prevent allergic post-muscle relaxant reactions (40). Sánchez Palacios considered that testing for all patients was not justified due to the small number of patients who had allergic reactions (41).

An article published in 2019 draws attention to the risk of mortality secondary to the administration of atracurium, independent of previous anesthesia with this neuromuscular drug. The mechanism can be by producing IgE upon previous contact with the drug or with quaternary ammonium moiety that can be found in some foods, as well as secondary to direct activation of cellular mast cells (42).

In patients whose risk of anaphylactic reactions is increased and the skin test is inconclusive, complementary tests such as basophil activation test (BAT) may be used (43).

In conclusion, succinylcholine is more allergenic than atracurium, the most affected being female patients. The subjects in the urban area and those under the age of 40 were statistically more affected only in the succinylcholine group. Overweight patients were the most susceptible to adverse reactions in both groups. Regarding the use of pre-operative skin test in all patients, we leave this topic open considering further studies are required in order to determine their efficacy.

\section{Acknowledgements}

Not applicable.

\section{Funding}

No funding was received. 


\section{Availability of data and materials}

The datasets used and/or analyzed during the current study are available from the corresponding author on reasonable request.

\section{Authors' contributions}

ORC and MNL contributed to the study design, participated in the entire review process and prepared the manuscript. DCV, MNM, RGC and NM contributed to the collection of the relevant literature, as well as the analysis and critical interpretation of the data. GS, OCC and AG conceived the study and drafted the manuscript. All authors read and approved the final version of the manuscript.

\section{Ethics approval and consent to participate}

This is a retrospective study based on the side effects to drugs that were already included in the treatment protocol, according to 'Morgan and Mikhail's Clinical Anesthesiology', and are commonly used for anesthesia in the clinic. Signed informed consent was obtained from each patient.

\section{Patient consent for publication}

Not applicable.

\section{Competing interests}

All the authors declare that they have no competing interests.

\section{References}

1. Gupta A, Srivastava U, Saxena A, Mittal A and Dwivedi Y: Severe anaphylactic reaction to atracurium. Indian $\mathrm{J}$ Pharmacol 44 : 144-145, 2012.

2. Mertes PM and Laxenaire MC: Allergy and anaphylaxis in anaesthesia. Minerva Anestesiol 70: 285-291, 2004.

3. Butterworth JF, Mackey DC and Wasnick JD: Morgan and Mikhail's Clinical Anesthesiology. McGraw Hill, New York, NY, 2013.

4. Valcea L, Bulgaru-Iliescu D, Burlea SL and Ciubara A: Patient's rights and communication in the hospital accreditation process. Rev Cercet Interv Soc 55: 260-270, 2016.

5. Bumbacea RS, Popa LG, Orzan OA, Voiculescu VM and Giurcaneanu C: Clinical and therapeutic implications of the association between chronic urticaria and autoimmune thyroiditis. Acta Endocrinol (Buchar) 10: 595-604, 2014.

6. Mertes PM, Laxenaire MC and Alla F; Groupe d'Etudes des Réactions Anaphylactoïdes Peranesthésiques: Anaphylactic and anaphylactoid reactions occurring during anesthesia in France in 1999-2000. Anesthesiology 99: 536-545, 2003.

7. Claudius C, Garvey LH and Viby-Mogensen J: The undesirable effects of neuromuscular blocking drugs. Anaesthesia 64 (Suppl 1): 10-21, 2009.

8. Tatu AL and Nwabudike LC: Bullous reactions associated with COX-2 inhibitors. Am J Ther 24: e477-e480, 2017.

9. Tatu AL, Elisei AM, Chioncel V, Miulescu M and Nwabudike LC: Immunologic adverse reactions of $\beta$-blockers and the skin. Exp Ther Med 18: 955-959, 2019.

10. Ciobotaru OR, Voinescu DC, Ciobotaru OC, Voicu D and Arbune M: Expression of p53 and Ki-67 in distal oesophageal and gastric cardia adenocarcinomas. Rom Biotechnol Lett 20: 10800-10808, 2015.

11. Spoerl D, Nigolian H, Czarnetzki C and Harr T: Reclassifying anaphylaxis to neuromuscular blocking agents based on the presumed patho-mechanism: IgE-mediated, pharmacological adverse reaction or 'innate hypersensitivity'? Int J Mol Sci 18: E1223, 2017
12. Ghiță MA, Căruntu C, Rosca AE, Căruntu A, Moraru L, Constantin C, Neagu M and Boda D: Real-time investigation of skin blood flow changes induced by topical capsaicin. Acta Dermatovenerol Croat 25: 223-227, 2017.

13. Branisteanu D, Caruntu C, Negrei C, Ghita MA, Caruntu A, Badarau AI, Buraga I, Boda D and Albu A: Capsaicin, a hot topic in skin pharmacology and physiology. Farmacia 63: 487-491, 2015.

14. De Pater GH, Florvaag E, Johansson SG, Irgens $\AA$, Petersen MN and Guttormsen AB: Six years without pholcodine; Norwegians are significantly less IgE-sensitized and clinically more tolerant to neuromuscular blocking agents. Allergy 72: 813-819, 2017.

15. Harper NJ, Cook TM, Garcez T, Farmer L, Floss K, Marinho S, Torevell H, Warner A, Ferguson K, Hitchman J, et al: Anaesthesia, surgery, and life-threatening allergic reactions: Epidemiology and clinical features of perioperative anaphylaxis in the 6th National Audit Project (NAP6). Br J Anaesth 121: 159-171, 2018.

16. Galvão VR, Giavina-Bianchi P and Castells M: Perioperative anaphylaxis. Curr Allergy Asthma Rep 14: 452, 2014.

17. Garvey LH: Old, new and hidden causes of perioperative hypersensitivity. Curr Pharm Des 22: 6814-6824, 2016.

18. Ciobotaru OR, Voinescu DC, Barna O, Barna I and Ciobotaru OC: Influence of the type of anaesthesia used, the diet and the consumption of sugar and alcohol on the intradermal skin test to morphine. Biotechnol Biotechnol Equip 29: 935-941, 2015.

19. Di Leo E, Donne PD, Calogiuri GF, Macchia L and Nettis E: Focus on the agents most frequently responsible for perioperative anaphylaxis. Clin Mol Allergy 16: 16, 2018.

20. Navinés-FerrerA,Serrano-CandelasE,LafuenteA,Muñoz-CanoR, Martín M and Gastaminza G: MRGPRX2-mediated mast cell response to drugs used in perioperative procedures and anaesthesia. Sci Rep 8: 11628, 2018.

21. Subramanian H, Gupta K and Ali H: Roles of Mas-related $\mathrm{G}$ protein-coupled receptor $\mathrm{X} 2$ on mast cell-mediated host defense, pseudoallergic drug reactions, and chronic inflammatory diseases. J Allergy Clin Immunol 138: 700-710, 2016.

22. Grigore O, Mihailescu AI, Solomon I, Boda D and Caruntu C: Role of stress in modulation of skin neurogenic inflammation. Exp Ther Med 17: 997-1003, 2019.

23. Căruntu C, Boda D, Musat S, Căruntu A and Mandache E: Stress-induced mast cell activation in glabrous and hairy skin. Mediators Inflamm 2014: 105950, 2014.

24. Ilie MA, Caruntu C, Lixandru D, Tampa M, Georgescu SR, Constantin MM, Constantin C, Neagu M, Zurac SA and Boda D: In vivo confocal laser scanning microscopy imaging of skin inflammation: Clinical applications and research directions. Exp Ther Med 17: 1004-1011, 2019.

25. Ilie MA, Caruntu C, Tampa M, Georgescu SR, Matei C, Negrei C, Ion RM, Constantin C, Neagu M and Boda D: Capsaicin: Physicochemical properties, cutaneous reactions and potential applications in painful and inflammatory conditions. Exp Ther Med 18: 916-925, 2019.

26. Filip-Ciubotaru F, Manciuc C, Stoleriu G and Foia L: NADPH Oxidase: Structure and activation mecanisms (Review). Note I. Rev Med Chir Soc Med Nat Iasi 120: 29-33, 2016.

27. Boda D, Negrei C, Nicolescu F and Badalau C: Assessment of some oxidative stress parameters in methotrexate treated psoriasis patients. Farmacia 62: 704-710, 2014.

28. McNeil BD, Pundir P, Meeker S, Han L, Undem BJ, Kulka M and Dong X: Identification of a mast-cell-specific receptor crucial for pseudo-allergic drug reactions. Nature 519: 237-241, 2015.

29. Koppert W, Blunk JA, Petersen LJ, Skov P, Rentsch K and Schmelz M: Different patterns of mast cell activation by muscle relaxants in human skin. Anesthesiology 95: 659-667, 2001.

30. Hariharan U, Shah SB and Bhargava AK: Local allergic reaction to atracurium besylate: An uncommon and unique reason. J Anesthesiol Clin Sci 4: 4-6, 2015.

31. Mertes PM, Lambert M, Guéant-Rodriguez RM, Aimone-Gastin I, Mouton-Faivre C, Moneret-Vautrin DA, Guéant JL, Malinovsky JM and Demoly P: Perioperative anaphylaxis. Immunol Allergy Clin North Am 29: 429-451, 2009.

32. Maranduca MA, Serban IL, Dima N, Badescu C, Ganceanu-Rusu R, Hurjui LL, Paduraru R, Tanase O, Parlapan A and Rezus C: Cardiovascular and metabolic comorbidities - therapeutic difficulties. Case report. Rev Med Chir Soc Med Nat Iasi 122: 304-308, 2018

33. Grecu C, Grecu A, Serban IL,Hurjui I, Delianu C, Maranduca MA, Popovici D, Gradinaru I, Mitrea M and Hurjui LL: Prevalence of nasal carriage of Staphylococcus aureus with special reference to number of methicillin resistance and antimicrobial evaluation among apparently people with good health status. Rev Med Chir Soc Med Nat Iasi 122: 819-825, 2018. 
34. Maranduca MA, Branisteanu D, Serban DN, Branisteanu DC, Stoleriu G, Manolache N and Serban IL: Synthesis and physiological implications of melanic pigments. Oncol Lett 17: 4183-4187, 2019.

35. Dewachter P, Chollet-Martin S, Mouton-Faivre C, de Chaisemartin L and Nicaise-Roland P: Comparison of basophil activation test and skin testing performances in NMBA allergy. J Allergy Clin Immunol Pract 6: 1681-1689, 2018.

36. Ilie MA,Caruntu C,Lupu M,Lixandru D, Tampa M,Georgescu SR, Bastian A, Constantin C, Neagu M, Zurac SA, et al: Current and future applications of confocal laser scanning microscopy imaging in skin oncology. Oncol Lett 17: 4102-4111, 2019.

37. Brănişteanu DE, Pintilie A, Andreş LE, Dimitriu A, Oanţă A, Stoleriu G and Brănisteanu DC: Ethiopatogenic hypotheses in lichen planus. Rev Med Chir Soc Med Nat Iasi 120: 760-767, 2016.

38. Schaas BA, Ivan S, Titianu M, Condratovici CP, Maier A and Schaas CM: Biochemical markers predicting the risk of gestational diabetes mellitus. Mater Plast 54: 133-136, 2017.

39. Ratiu MP, Purcarea I, Popa F, Purcarea VL, Purcarea TV, Lupuleasa D and Boda D: Escaping the economic turn down through performing employees, creative leaders and growth driver capabilities in the Romanian Pharmaceutical Industry. Farmacia 59: 119-129, 2011.
40. Petitpain N, Argoullon L, Masmoudi K, Fedrizzi S, Cottin J, Latarche C, Mertes PM and Gillet P; French Network of Regional Pharmacovigilance Centres: Neuromuscular blocking agents induced anaphylaxis: Results and trends of a French pharmacovigilance survey from 2000 to 2012. Allergy 73: 2224-2233, 2018.

41. Sánchez Palacios A, Ortiz Ponce M, Rodríguez Pérez A, Schamann Medina F and García Marrero JA: Modification of mediators of immune reaction after general anaesthesia. Allergol Immunopathol (Madr) 32: 352-360, 2004

42. Schumacher J: Fatal anaphylaxis to atracurium: A Case Report. A A Pract 12: 145-146, 2019.

43. Eberlein B, Wigand S, Lewald H, Kochs E, Ring J, Biedermann T and Darsow U: Utility of basophil activation testing to assess perioperative anaphylactic reactions in real-world practice. Immun Inflamm Dis 5: 416-420, 2017. International (CC BY-NC-ND 4.0) License. 